\title{
Design and Control of a Hybrid 48V/375V/400Vac AC/DC Microgrid
}

\author{
Carlos Gómez-Aleixandre, Pablo García, Ángel Navarro-Rodríguez and Geber Villa \\ Dept. of Electrical, Electronics, Systems \& Computers Engineering \\ University of Oviedo, LEMUR Group, Gijón, 33204, Spain \\ Email: gomeztcarlos@uniovi.es, garciafpablo@uniovi.es, navarroangel@uniovi.es, villageber@uniovi.es
}

\begin{abstract}
This paper presents a novel design and control for a hybrid 48 Vdc / 375 Vdc / 400 Vac AC/DC hybrid microgrid for a terminal distribution system. The proposed paper includes the selection of the topologies for the different power electronic converters involved in the hybrid microgrid as well as the proposed control system. Special attention is paid to the balance of the bipolar \pm 375 Vdc-grid when unbalanced loads are applied, both in the $\mathrm{AC}$ and DC grids. Different scenarios are considered in order to evaluate the effect of contingencies in the different converters used for the energy distribution. Two different scenarios are evaluated by simulation results, focusing in the transient response under different loads and distributed generation elements.
\end{abstract}

\section{INTRODUCTION}

The future electricity grid is gradually moving in the direction of DC distribution, due the envisaged lower distribution losses (as compared with AC distribution) and the more efficient integration of renewables and distributed resources [1][3]. Due to the random behavior of such renewable generation units, a major challenge for a reliable grid performance is to increase the wind/solar power share, while achieving power balance and voltage and frequency stability. Such intermittent behavior of the renewable generators can be effectively compensated by the inclusion of Energy Storage Systems (ESS) in the distribution grid [3]. The evolution in power electronics and control technologies has enabled the development of DC Low-Voltage (LV) microgrids. This eases the integration of ESS, also enhancing the performance of DC grids at building level, by reducing costs and increasing reliability [3], [4]. However, it is still unclear the pathway from AC conventional distribution systems to these modern DC or DC/AC grids. Table I shows the main conclusions arising from the current situation about DC distribution, given by regulations and directives, also considering associations and committees, as well as the experiences in some key facilities.

Therefore, it is reasonable to think that the change is not going to be a drastic switch from a contrasted AC system,

The present work has been partially supported by the predoctoral grants program FPU for the formation in university teaching of Spain MECD under the grant IDs FPU16/05313 and FPU16/06829 and program Severo Ochoa for the formation in research and university teaching of Principado de Asturias PCTI-FICYT under the grant ID BP14-135. This work also was supported in part by the Research, Technological Development and Innovation Program Oriented to the Society Challenges of the Spanish Ministry of Economy and Competitiveness under grant ENE2016-77919-R and by the European Union through ERFD Structural Funds (FEDER).
TABLE I

DC DISTRIBUTION ALTERNATIVES.

\begin{tabular}{|c|c|c|}
\hline Standard & DC voltage $(\mathrm{V})$ & Application \\
\hline $\begin{array}{l}\text { EMerge Alliance } \\
\text { Standard for } \\
\text { commercial } \\
\text { buildings }\end{array}$ & 24 & $\begin{array}{l}\text { DC power distribution } \\
\text { in commercial buildings }\end{array}$ \\
\hline $\begin{array}{l}\text { EMerge Alliance } \\
\text { Standard for data } \\
\text { centres }\end{array}$ & 380 & $\begin{array}{l}\text { Hybrid use of AC and } \\
\text { DC power within data } \\
\text { centres and telecom } \\
\text { central offices }\end{array}$ \\
\hline $\begin{array}{l}\text { EU Telecom } \\
\text { Standard ETSI EN } \\
300132-3-1\end{array}$ & 400 & $\begin{array}{l}\text { Distribution networks } \\
\text { supplying telecom and } \\
\text { datacom equipment }\end{array}$ \\
\hline $\begin{array}{l}\text { IEEE } 802.3 \\
\text { Standard }\end{array}$ & 50 & $\begin{array}{l}\text { Applications that } \\
\text { receive both power and } \\
\text { high-speed data through } \\
\text { the same RJ45 } \\
\text { connector }\end{array}$ \\
\hline $\begin{array}{l}\text { European directive } \\
\text { EU LDV 2006/95EC }\end{array}$ & $75-1500$ & $\begin{array}{l}\text { Encourages } \\
\text { manufacturers and other } \\
\text { agents for } \\
\text { harmonisation but } \\
\text { without fixing any } \\
\text { voltage level }\end{array}$ \\
\hline $\begin{array}{l}\text { SEG4 group, } \\
\text { IEC60038 }\end{array}$ & $12 / 48 / 380$ & $\begin{array}{l}\text { Provides a } \\
\text { recommendation for } \\
\text { different voltage levels }\end{array}$ \\
\hline $\begin{array}{l}\text { National Electrical } \\
\text { Code (NEC) } \\
\text { NFPA70 }\end{array}$ & 60 & $\begin{array}{l}\text { Low voltage low power } \\
\text { devices like sensors or } \\
\text { led lighting }\end{array}$ \\
\hline MIL-STD-1399 & $28 / 155 / 270 / 375 / 650$ & Shipboard applications \\
\hline
\end{tabular}

with a history over 100 years, to a completely new distribution paradigm. The most feasible solution seems to be the adoption of hybrid AC/DC power system schemes with both $\mathrm{AC}$ and DC subsystems based on current AC infrastructures [1]. This hybrid approach has the following objectives: 1) use of PEC in order to provide redundancy of power flows and thus increasing the grid resiliency [5], 2) reducing the number of required power conversion stages for the connection of loads and distributed resources, thus increasing the efficiency. So far, a manifold of purely AC or DC microgrid topologies have been proposed, as well as some experiences dealing with hybrid topologies. In [6], DC and some existing hybrid microgrid topologies are analyzed. The most common hybrid structure is the typical AC/DC hybrid microgrid in which two different buses (AC and DC) are connected through one or more converters. DC loads and generators are connected to 
the DC bus, while AC loads and generators are coupled with the AC line. Usually, in these kinds of schemes, the AC line is connected to the main grid. Other proposals consider AC rings connected to a substation and AC/DC converters connected to this outer AC rings feeding DC small microgrids. There are few experiences considering complex topologies combining $\mathrm{AC}$ and DC structures [4], [6], [7]. The use of these kind of networks inside buildings is another trend that could lead to the massive use of such hybrid technologies. For instance in [8], the building main network is AC but there is a small DC radial microgrid for connecting the PV generation, ESS and also dedicated DC loads. Regarding the control implementation in hybrid microgrids, it is critical to analyze the transient response and the power sharing among the $\mathrm{DC}$ and $\mathrm{AC}$ buses [9], [10].

\section{Proposed HYBRID DC/AC MICROGRID}

The hybrid AC/DC network architecture proposed in this paper is shown in Fig. 1. In there, the hybrid distribution system departures from the output port of a three-port solid state transformer with one input port connected to the main AC grid and the other to a central energy storage system [11]. From there, a $\pm 375 \mathrm{Vdc}$ distribution line is connected. In parallel, a power converter (Header PEC, $60 \mathrm{kVA}$ ) generates two parallel 400 Vac feeders, which distribute the power downstream. The Header PEC (HPEC) is built by two parallelconnected 3-level NPC converters which are also responsible of keeping the two DC-buses ( $375 \mathrm{~V}$ each) balanced. All the elements from the high-frequency transformer up to the HPEC are envisaged to be installed in the next generation transformation center. From the main DC-line two identical Ring PEC (RPEC) are connected, providing an alternative path for the AC distribution but also generating a $48 \mathrm{~V} \mathrm{DC}$ bus for the internal DC distribution inside a building block. These two RPEC shall be installed in the main connection of a set of buildings to the grid. Finally, the Tail PEC (TPEC) allows for generating a ring between the two feeders, thus enabling an alternative distribution path in the case the other feeder is disabled. The converters could be installed at the next transformation center in the distribution grid.

The DC line connecting the point of connection of the HPEC to the RPEC is considered as a pure resistive line with three identical conductors: one for the +375 DC-bus rail of $500 \mathrm{~m}$ length and two for ground and -375 DC-bus rail of $1000 \mathrm{~m}$ length. They are modelled for a maximum voltage drop of $3 \%$ at the end of the $1000 \mathrm{~m}$ line, assuming Ring \#2 $\mathrm{PEC}$ is working at full power. Both AC feeders are modelled for $1000 \mathrm{~m}$ length and for a maximum voltage drop of $3 \%$ at the end of the line, assuming and $\mathrm{X} / \mathrm{R}$ ratio of 5 .

\section{A. Header PEC}

The header power electronic converter is the coordination converter for the hybrid DC/AC microgrid. Its functions include: 1) to provide a distributed $\pm 375 \mathrm{Vdc}$ for the main $\mathrm{DC}$ grid path; 2) to generate two different 4-wire 3-phase $400 \mathrm{~V}$ lines for the main AC grid distribution; 3) to deal with the load disturbances, both in the AC and DC grids. It will be of critical importance for the converter to be able to deal with unbalances in the distributed DC-link, which is connected to the two Rings, Ring\#1 and Ring\#2 converters, shown in Fig. 1. As it can be seen these two converters provide an alternative path for the 400 Vac grid as well as they are the responsible of generating the $48 \mathrm{Vdc}$ links. Considering the two converter can have different loads, the demanded energy from the two DC-link rails, +375/gnd and gnd/- 375 will be different. The reason of the dual DC-link distribution instead of a single $750 \mathrm{Vdc}$ link is to have a more reliable energy link path, being possible that even if one of the DC-links presents a fault condition, the other to continue working.

According to the design constraints, the selected topology for the HPEC is a dual 3-level 4-wire 3-phase NPC converter. The reason about this topology is that is has a reasonable cost for the target power (60 kVA), it provides a split DC-link to generate the two distribution $375 \mathrm{Vdc}$ links and it allows for a balancing control method able to deal both with 3-phase and single phase loads and generation units.

The control system is shown in Fig. 2. Details about cross-coupling and feedforward terms, normalization and nonlinear compensation [9] for the duty calculation are omitted due to space constraints. The DC-link balancing scheme is implemented according to the one developed in [12].

\section{B. Ring converter}

The two ring converters shown in Fig. 1 have the same rated power, $20 \mathrm{kVA}$, and they generate, from the two different main DC-grid, a connection to the two 400 Vac feeders and two independent $48 \mathrm{Vdc}$ grids. The converter has an internal bidirectional stage for generating a $750 \mathrm{~V}$ DC-link from the $375 \mathrm{Vdc}$, a 2-level 4-wire 3-phase DC/AC stage for the interconnection with the $\mathrm{AC}$ grid and a bidirectional DC/DC $375 / 48 \mathrm{~V}$ for the generation of the $48 \mathrm{~V}$ internal building grid. Regarding the control system, Fig. 3 shows the required control loops. As it can be seen, the converter has to be able to synchronize with the $\mathrm{AC}$ grid generated by the HPEC, contributing to the energy demands. For the case of the $48 \mathrm{Vdc}$ link, the control system generates an stiff bidirectional link, able to deal with the integration of small distributed generation and energy storage systems.

\section{Tail converter}

The TPEC shown in Fig. 1 is a 2-level 4-wire 3-phase back-to-back converter used for the interconnection of the two $\mathrm{AC}$ feeders, thus generating a ringed distribution system. It is worth noting that the operation of that converter, considers the isolated operation of the grid because of the shown local energy storage.

\section{MICROGRID OPERATION MODES}

The operation of the hybrid DC/AC microgrid can be explained by several modes, all of those here described. For the explanation of the modes, it is needed first to explain the possible states for the distribution lines. 


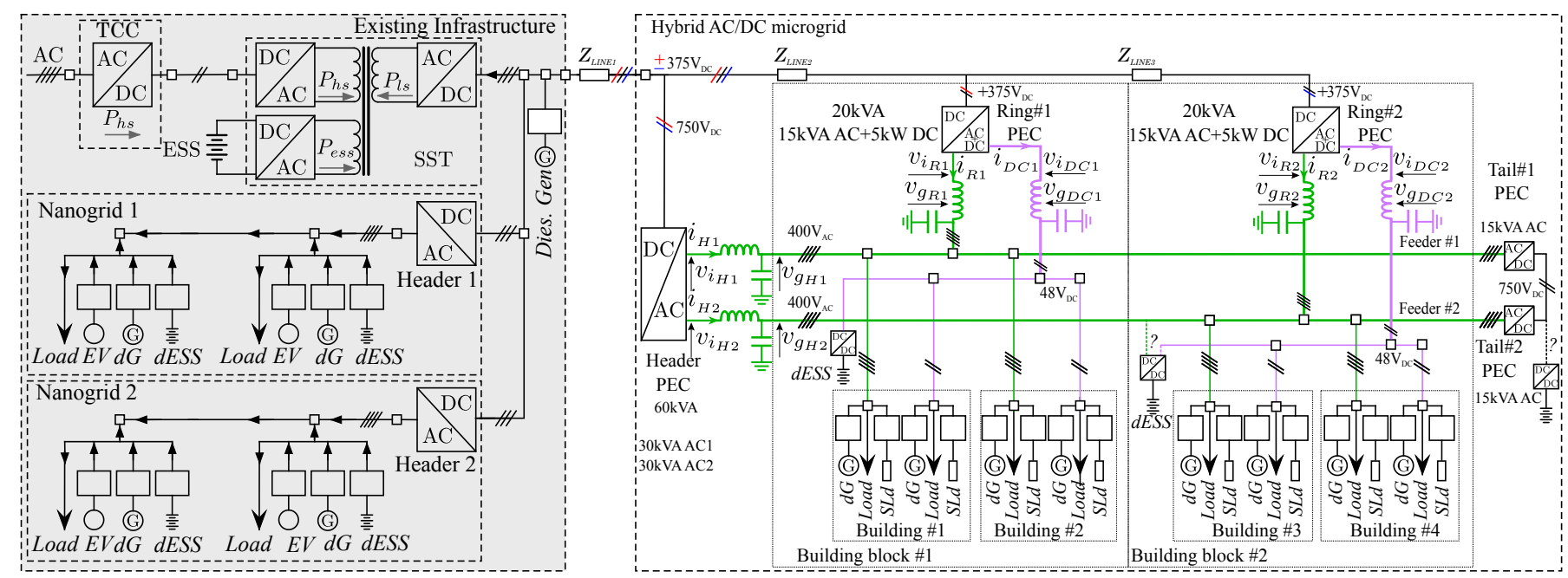

Fig. 1. Proposed system level grid infrastructure.

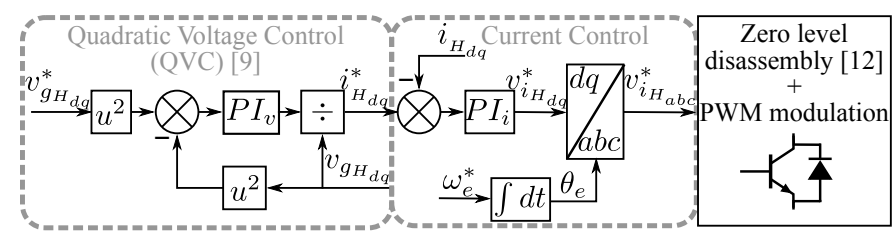

Fig. 2. Header converter control diagram.

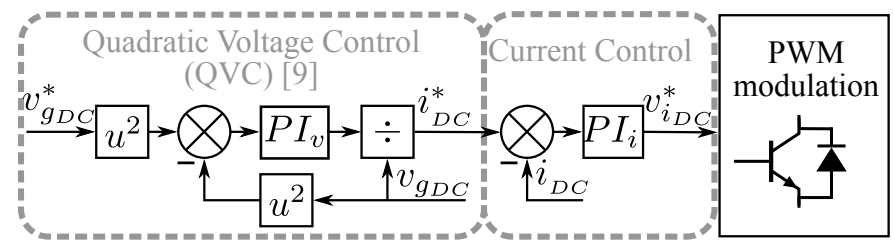

(a) $\mathrm{DC} / \mathrm{DC}$ stage from $375 \mathrm{Vdc}$ bus to $48 \mathrm{Vdc}$.

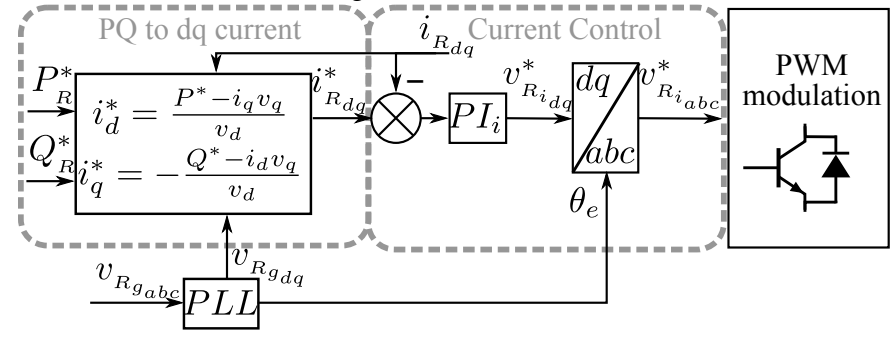

(b) DC/AC stage, from $375 \mathrm{Vdc}$ to $400 \mathrm{Vac}$ (PQ mode).

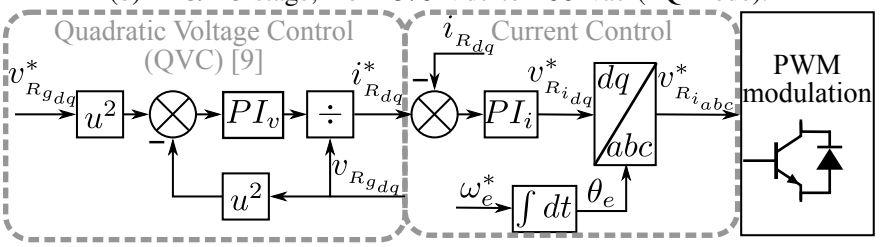

(c) DC/AC stage, from $375 \mathrm{Vdc}$ to $400 \mathrm{Vac}$ (slack mode).

Fig. 3. Ring converter control diagram.

- Connection to the main AC grid. When the main AC grid is connected, the energy to the distribution system can be provided by the AC grid or by the central energy storage connected to the solid-state transformer. When disconnected, the distribution system works in islanded mode using the central energy storage, the internal gen- eration and the distributed energy storage systems.

- DC/AC main feeders. The two AC and the two DC feeders can operate simultaneously or independently when a contingency occurs. Under any event condition, all the loads have to be operate normally. Alternative energy path are provided for the different loads by the ring and tail converters and from the local energy storage installed at the $48 \mathrm{~V}$ distribution.

According to this, the following modes are considered:

- HPEC fully operational. In this case, the two AC and DC feeders are operational. The HPEC behaves like a dual slack converter, generating the two AC feeders voltages. Both NPC converters participate in the balancing of the dual DC-link. The two ring converters work in $\mathrm{P} / \mathrm{Q}$ mode, being a complementary path for supplying the loads when needed. The TPEC could be either in operational mode or disconnected.

- HPEC AC outputs not operational. One or the two AC outputs could be disconnected for a variety of reasons. Whenever an AC output is disconnected, the corresponding Ring converter changes its operation mode from P/Q to slack. The TPEC converter is in operational mode providing alternative paths for the energy. DC feeders continue fully operational.

- Fault in the DC feeders. One or two of the DC feeders could have a contingency. In that case, the corresponding RPEC can not operate. AC feeders continue its normal operation. $48 \mathrm{~V}$ bus is generated internally from the dESS.

- Disconnection of the main DC-link. The main $750 \mathrm{~V}$ dc link is generated by the output port of the solidstate transformer. If a fault occurs in there, both in the connection to the mains and in the central energy storage, the HPEC and the RPEC can not operate. In that case, the TPEC with the local storage and the dESS connected to the $48 \mathrm{~V}$ link are the responsible for the grid generation. 
TABLE II

CONVERTER PARAMETERS.

\begin{tabular}{|c|c|c|c|}
\hline Converter & HPEC - AC & RPEC - AC & RPEC - DC \\
\hline $\mathrm{L}_{\text {filter }}(\mathrm{mH})$ & 1.68 & 3.37 & 1.47 \\
\hline $\mathrm{R}_{\text {filter }}(\mathrm{m} \Omega)$ & 35.3 & 70.5 & 30.7 \\
\hline $\mathrm{C}_{\text {filter }}(\mathrm{mF})$ & 0.5 & 0.1 & 5 \\
\hline $\mathrm{C}_{\text {bus }}(\mathrm{mF})$ & 5 & 5 & 5 \\
\hline $\mathrm{BW}_{\mathrm{i}}(\mathrm{Hz})$ & 500 & 500 & 500 \\
\hline $\mathrm{BW}_{\mathrm{v}}(\mathrm{Hz})$ & 50 & 50 & 50 \\
\hline
\end{tabular}

\section{Simulation Results}

For testing the proper operation of the proposed architecture, two of the proposed modes have been simulated using Simulink/Matlab.

The simulations are based on the scheme shown in Fig. 1, with some simplifications for the initial evaluation: 1) the 750 $\mathrm{Vdc}$ bus is generated from a bi-directional DC/DC converter, 2) the tail converters are not considered.

The details of the different converter output LC filter parameters as well as the control loop bandwidths are shown in Table II.

\section{A. HPEC fully operational}

Each of the two parallel-connected 3-level NPC converter operates in slack mode, being responsible for the voltage control in Feeder \#1 and Feeder \#2 respectively (to a fixed value of $400 \mathrm{Vrms}$ ), apart from the aforementioned DC-bus balancing in which both converters are participating.

The two ring converters are connected to the two $400 \mathrm{Vac}$ feeders (operating in P/Q mode) and to the $48 \mathrm{Vdc}$ internal building grid (operating in DC slack mode).

Three different load cases are analyzed: 1) Balanced case. Changes in the references and in the loads are balanced for both feeders and the ring converters, having the same power demand in both DC-link rails. 2) Unbalanced DCbus. Changes in the reference commands and in the loads are applied only to Building block \#2, thus generating a difference between the power demand in both DC-link rails which induces an unbalance that has to be compensated by the HPEC NPC converter. 3) Unbalanced AC-load. A singlephase load is connected at Feeder \#2, generating an unbalance in that $\mathrm{AC}$ grid.

The time intervals for the complete sequence are as follows: 1) $\mathbf{t}=0.1 \mathrm{~s}, \mathrm{P}$ reference in DC/AC stage of both ring converters changes from 0 to $-8 \mathrm{~kW}, 2) \mathbf{t}=\mathbf{0 . 2} \mathbf{s}$, a $4 \mathrm{~kW}$ load is connected in each $48 \mathrm{Vdc}$ internal building grid, 3) $\mathbf{t}$ $=0.3 \mathrm{~s}$, Q reference in DC/AC stage of both ring converters changes from 0 to $12 \mathrm{kvar}, 4) \mathbf{t}=\mathbf{0 . 5} \mathbf{~ s}$, a $12 \mathrm{~kW}$ load is connected in each $400 \mathrm{Vac}$ feeder, 5) $\mathbf{t}=\mathbf{0 . 7} \mathbf{s}$, P reference in DC/AC stage of Building block \#2 ring converter changes from -8 to $10 \mathrm{~kW}, 6) \mathbf{t}=\mathbf{0 . 8} \mathbf{s}$, Q reference in DC/AC stage of Building block \#2 ring converter changes from 12 to -4 kvar, 7) $\mathbf{t}=\mathbf{1 . 1} \mathrm{s}$, load connected in Building block \#2 $48 \mathrm{Vdc}$ grid changes from 4 to $1 \mathrm{~kW}, 8) \mathbf{t}=\mathbf{1 . 2} \mathbf{s}$, load connected in Building block \#2 400 Vac feeder changes from 12 to 2

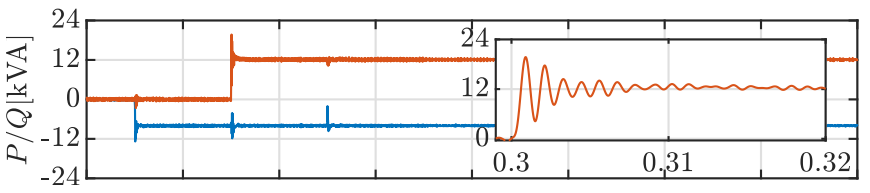

(a) Ring converter in building block \#1.

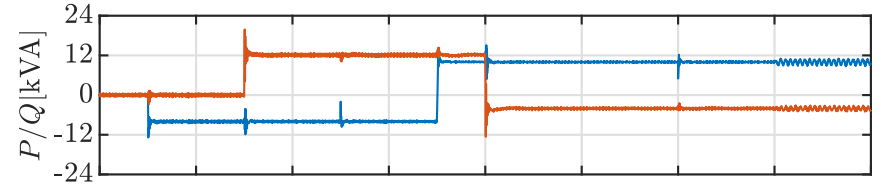

(b) Ring converter in building block \#2.

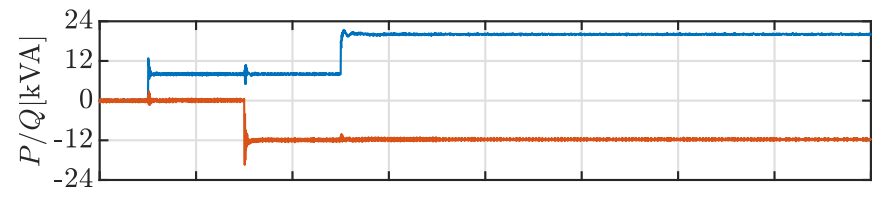

(c) HPEC connected to Feeder \#1.

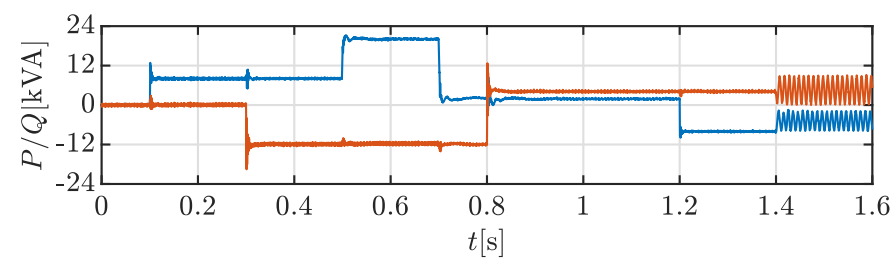

(d) HPEC connected to Feeder \#2.

Fig. 4. Active and reactive power output (blue, active power; red, reactive power).

$\mathrm{kW}$, 9) $\mathbf{t}=\mathbf{1 . 4} \mathrm{s}$, a single-phase $4 \mathrm{~kW}$ load is connected in Building block \#2 400 Vac feeder.

In Fig. 4a and 4b, the active and reactive power output for the DC/AC stage of each ring converter is shown. It can be seen that the control system is able to follow the references with a fast response but with some overshoot (as shown in the zoom area). It also has deviations from the reference values when loads are connected in the corresponding feeder, causing some oscillations, but the control is able to fast recovery.

In Fig. $4 \mathrm{c}$ and $4 \mathrm{~d}$, the active and reactive power delivered by the HPEC to each of the 400 Vac feeders is shown. Since they operate in slack mode, they have to provide all the feeder net consumption (sum of all loads consumption, considering ring converters as loads, since they operate in P/Q mode) to maintain an stiff voltage value. The response in all the demand changes is really fast.

The effect of a single-phase load is shown in Fig. 4d. In there, a single-phase load is connected to Feeder \#2. As expected, a pulsating power demand at twice the fundamental frequency appears in the active and reactive power components delivered by the HPEC.

Fig. 5 shows HPEC voltage output in $d q$ reference frame. Despite the transient oscillations when the load changes, the control is able to keep the voltage really close to the reference value $(230 \sqrt{2}=325 \mathrm{~V}$ for the $d$-axis; $0 \mathrm{~V}$ for the $q$-axis $)$.

Besides that, it can be seen that the connection of single- 


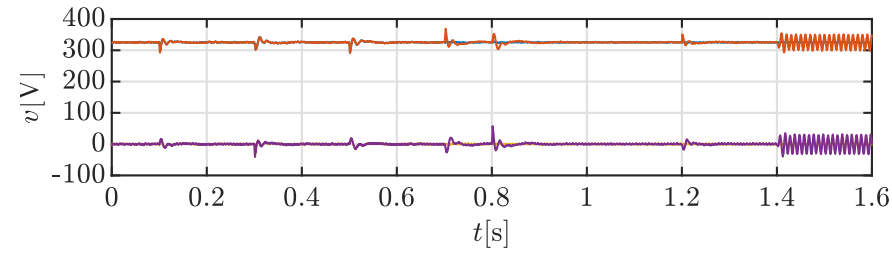

Fig. 5. HPEC voltage output in dq reference frame for both AC feeders (blue and red, $\mathrm{d}$ voltage for Feeder $\# 1$ and $\# 2$; yellow and purple, $\mathrm{q}$ voltage for Feeder \#1 and \#2).

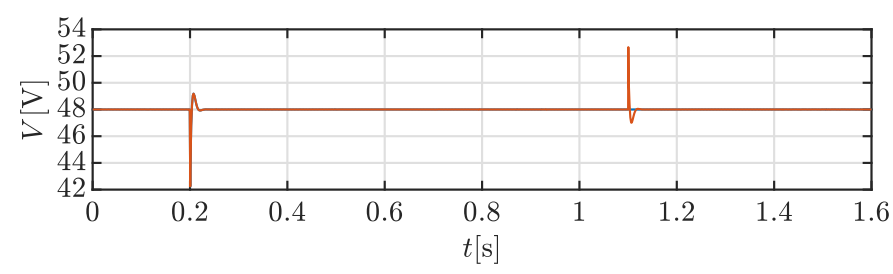

Fig. 6. DC/DC stage of ring converters voltage output for both $48 \mathrm{Vdc}$ internal building grids (blue and red, voltage for Building block \#1 and \#2).

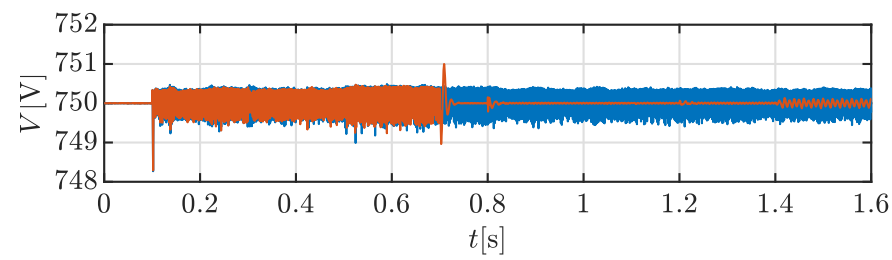

Fig. 7. Voltage after intermediate step for boosting from 375 to $750 \mathrm{Vdc}$ to connect DC-bus with AC-feeder (blue and red, voltage for Building block \#1 and \#2).

phase loads causes a $100 \mathrm{~Hz}$ oscillation to appear in the steadystate. This is the $-50 \mathrm{~Hz}$ negative-sequence component resulting from the unbalanced single-phase load (when represented in the synchronous reference frame, is seen as $100 \mathrm{~Hz}$ ).

Fig. 6 shows the voltage output in the two $48 \mathrm{Vdc}$ internal building grids. It can be seen that the DC/DC stage of the ring converters is able to control the voltage. The sags appearing when a new load is connected is recovered in short-time and the variation of the voltage value is acceptable, considering that they appear after a sudden connection for a $80 \%$ load of the power converter.

Fig. 7 shows the $750 \mathrm{Vdc}$ DC-link voltage in both ring converters. The control is able to control the voltage properly, only with some deviations (not very significant) when changes in the power reference for the corresponding ring converter are applied. The shown ripple has a small peak-to-peak value when compared with the rated voltage (around $1 \mathrm{~V}$ for a rated voltage of $750 \mathrm{~V}$ ).

In Fig. 8, voltage in both 375 DC-buses is shown. It can be seen that the balancing control implemented at the NPC is able to keep both buses stable, even though a small voltage sag can be seen when a load of $12 \mathrm{~kW}$ is connected to each AC feeder (at $\mathrm{t}=0.5 \mathrm{~s}$ ).

In Fig. 9a, current output of HPEC converter connected to Feeder \#2 is shown. When there is no unbalance in the load, the current has low THD $(1.31 \%)$, close to a perfect balanced-

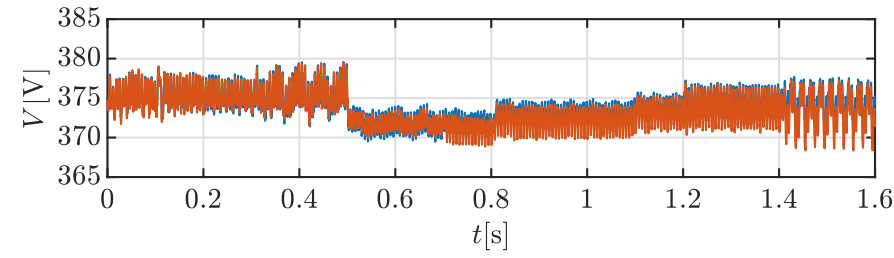

Fig. 8. Voltage in both DC-buses (blue and red, voltage in DC-bus 1 and 2).

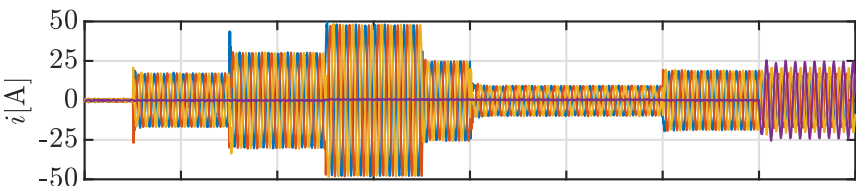

(a) HPEC connected to Feeder \#2.

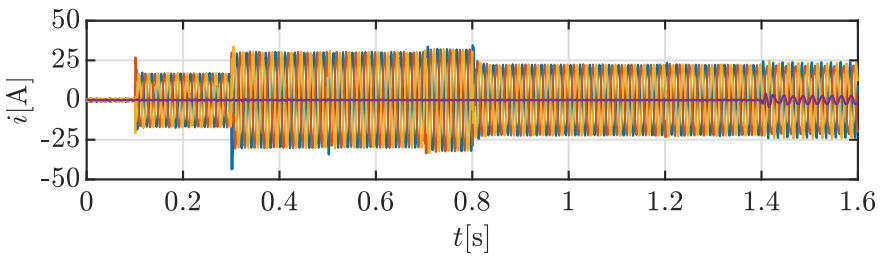

(b) Ring converter connected to Feeder \#2.

Fig. 9. Current output (blue, phase a; red, phase b; yellow, phase c; purple, neutral conductor).

sinusoidal system, with negligible current flowing through neutral conductor. Once the single-phase load is connected, an important amount of current is flowing through the neutral conductor and currents no longer form a balanced system.

After the single-phase load is connected, the current flows through the neutral conductor and the system is not longer balanced. The consequences of this load unbalance can be seen in $9 \mathrm{~b}$. At $\mathrm{t}=1.4 \mathrm{~s}$ (single-phase load connection), the current in the inverter becomes unbalanced due to the negative sequence component in the voltage controlled by the HPEC.

\section{B. Disconnection of one HPEC ac outputs}

In this second simulation, the disconnection of one of the HPEC AC feeders (\#2) is studied. In this case, the ring converter connected to that feeder switches to slack mode control to keep the voltage level of the feeder at the reference valuee. Apart from that, only one of the two HPEC NPC converters can contribute to balance the DC-buses.

The simulation conditions (reference changes, load connections,...) are the same than in the previous simulation except for those regarding to Feeder \#2. The sequence in that feeder now is: 1) $\mathbf{t}=\mathbf{0 . 1} \mathbf{~ s}$, connection of a 10 kvar capacitive load, 2) $\mathbf{t}=\mathbf{0 . 3} \mathbf{s}$,, connection of a $6 \mathrm{~kW}$ resistive load, 3) $\mathbf{t}=$ $0.8 \mathbf{s}$, reduction of resistive load from 6 to $2 \mathrm{~kW}, 4) \mathbf{t}=\mathbf{1} \mathbf{s}$, reduction of capacitive load from 10 to 4 kvar, 5) $\mathbf{t}=\mathbf{1 . 4} \mathbf{~ s}$, connection of a $2 \mathrm{~kW}$ single-phase resistive load.

In Fig. 10, the active and reactive power delivered by ring converter \#2 are shown. Since this converter is now the slack bus of this feeder, it has to provide all the power demand to keep the voltage level of the feeder. The effect of the single- 


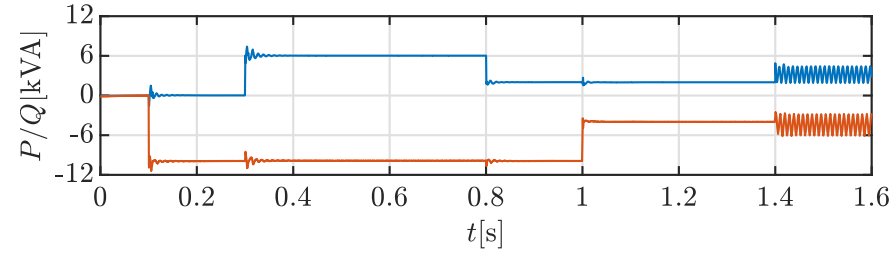

Fig. 10. Ring converter in building block \#2 active and reactive power output (blue, active power; red, reactive power).

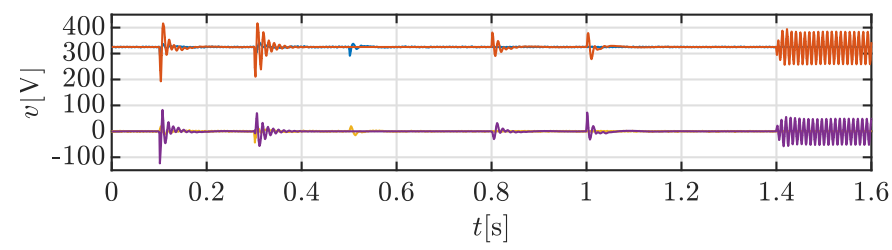

Fig. 11. HPEC voltage output in dq reference frame for both AC feeders (blue and red, d voltage for Feeder \#1 and \#2; yellow and purple, q voltage for Feeder \#1 and \#2).

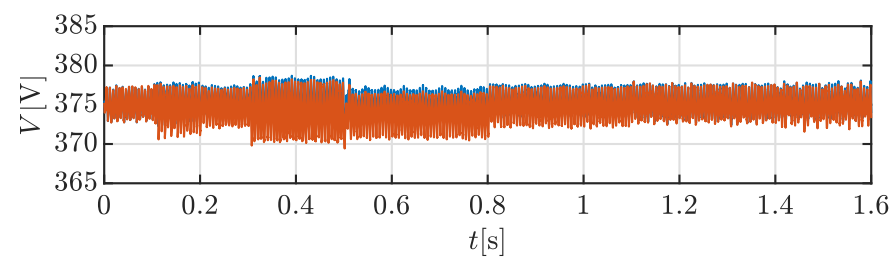

Fig. 12. Voltage in both DC-buses (blue and red, voltage in DC-bus 1 and 2).

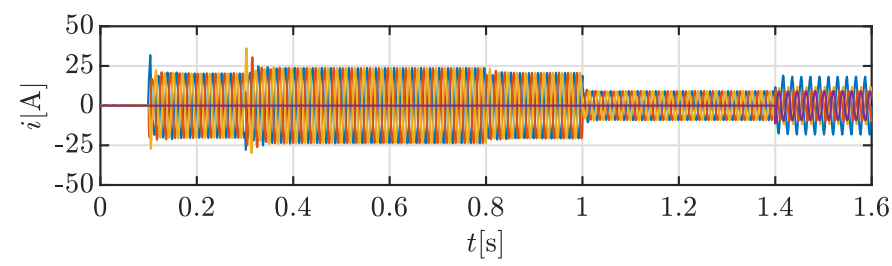

Fig. 13. Ring converter current output (blue, phase a; red, phase b; yellow, phase c; purple, neutral conductor).

phase load can be appreciated as a pulsating power demand with twice the fundamental frequency.

In Fig. 11, voltages in both $\mathrm{AC}$ feeders are shown. It can be seen that oscillations in Feeder \#2 are much more significant. This is normal since the converter acting as a slack for that feeder has less rated power so it is more affected by the sudden changes in power demand.

In Fig. 12, voltage in both DC-buses is shown. It can be seen that even though only one of the HPEC NPC converters is now working for balancing the DC-buses, it is able to maintain a value close to the reference level with almost no difference between the voltage of each bus.

Finally, in Fig. 13, current output for the ring converter connected to Feeder \#2 is shown. The system is able to provide balanced currents with low distortion, except when the single-phase load is connected (the currents become clearly unbalanced and current flows through neutral conductor).

The results related to Feeder \#1 and the $48 \mathrm{Vdc}$ internal building grid are really similar to the ones obtained in the previous simulation, so they are not shown.

\section{CONCLUSION}

In this paper, a novel architecture for a hybrid DC/AC microgrid, including the power converters topologies and control has been analyzed. A technique for the balancing of the two DC feeders, provided by a 3-level multiport converter has been successfully tested. Different operating modes, having reliability as the key design factor have been identified. From those, two have been successfully demonstrated by simulation. In all the cases, a good dynamic response under balanced/unbalanced loads has been demonstrated.

Future works will include a complete study for all the proposed operating modes as well as the analysis of the transition between them. Collaborative operation for the different converters, considering droop control instead of slack mode is also aim of future developments. An experimental test rig is currently being built for the validation of proposed hybrid distribution system.

\section{REFERENCES}

[1] P. Wang, L. Goel, X. Liu, and F. H. Choo, "Harmonizing ac and dc: A hybrid ac/dc future grid solution," IEEE Power and Energy Magazine, vol. 11, no. 3, pp. 76-83, May 2013.

[2] P. Fairley, "Dc versus ac: The second war of currents has already begun [in my view]," IEEE Power and Energy Magazine, vol. 10, no. 6, pp. 104-103, Nov 2012.

[3] A. Bindra, "Projecting the evolution of power electronics: Highlights from feppcon viii," IEEE Power Electronics Magazine, vol. 3, no. 1, pp. 32-44, March 2016.

[4] N. Eghtedarpour and E. Farjah, "Power control and management in a hybrid ac/dc microgrid," IEEE Transactions on Smart Grid, vol. 5, no. 3, pp. 1494-1505, May 2014.

[5] C. Marnay, H. Aki, K. Hirose, A. Kwasinski, S. Ogura, and T. Shinji, "Japan's pivot to resilience: How two microgrids fared after the 2011 earthquake," IEEE Power and Energy Magazine, vol. 13, no. 3, pp. 4457, May 2015.

[6] L. Jia, Y. Zhu, and Y. Wang, "Architecture design for new ac-dc hybrid micro-grid," in 2015 IEEE First International Conference on DC Microgrids (ICDCM), June 2015, pp. 113-118.

[7] A. A. Eajal, E. F. El-Saadany, M. F. Shaaban, and K. Ponnambalam, "Stochastic energy coordination in hybrid ac/dc smart grids," in 2015 IEEE Electrical Power and Energy Conference (EPEC), Oct 2015, pp. $158-163$.

[8] P. Arboleya, P. Garcia, B. Mohamed, and C. GonzalezMoran, "Distributed resources coordination inside nearly-zero energy buildings providing grid voltage support from a symmetrical component perspective," Electric Power Systems Research, vol. 144, pp. 208 - 214, 2017. [Online]. Available: http://www.sciencedirect.com/science/article/pii/S0378779616304862

[9] A. Navarro-Rodríguez, P. García, R. Georgious, and J. García, "Adaptive active power sharing techniques for dc and ac voltage control in a hybrid dc/ac microgrid," IEEE Transactions on Industry Applications, vol. 55, no. 2, pp. 1106-1116, March 2019.

[10] A. Navarro-Rodríguez, P. García, C. Blanco, R. Georgious, and J. García, "Cooperative control in a hybrid dc/ac microgrid based on hybrid dc/ac virtual generators," in 2018 IEEE Energy Conversion Congress and Exposition (ECCE), Sep. 2018, pp. 1156-1163.

[11] P. García, P. Arboleya, B. Mohamed, and A. A. C. Vega, "Implementation of a hybrid distributed/centralized real-time monitoring system for a dc/ac microgrid with energy storage capabilities," IEEE Transactions on Industrial Informatics, vol. 12, no. 5, pp. 1900-1909, Oct 2016.

[12] C. Wang, Z. Li, X. Si, and H. Xin, "Control of neutral-point voltage in three-phase four-wire three-level npc inverter based on the disassembly of zero level," CPSS Transactions on Power Electronics and Applications, vol. 3, no. 3, pp. 213-222, Sep. 2018. 